\section{A Deuterium Effect in Insect Attraction}

\author{
Ryozo Sugawara, Yasuhira Tominaga \\ and Yoshiaki IIDA \\ Institute of Applied Biochemistry, The University \\ of Tsukuba, Sakura-mura Niihari-gun, \\ Ibaraki-ken 300-31, Japan
}

Received November 2, 1977

The attractancy of propyl cyclohexaneacetate to the German cockroach has been disclosed by a comparative trap test under field conditions. ${ }^{1)}$ The molecule was regarded as consisting of a head (cyclohexane ring) and a tail (a side chain that incorporates ester linkage). The structure of the tail was modified with regard to a number of parameters. ${ }^{2)}$ The ring was converted into variously unsaturated forms. ${ }^{3)}$ Their activities were comparatively tested within various groups of congeners. The structure-activity relationships thus derived indicated a multipoint interaction that includes the ax.C-H bonds at $\mathrm{C}_{2}$ and $\mathrm{C}_{6}$ on the ring, the terminal methyl group in the side chain, and the ester oxygen (Fig. 1).

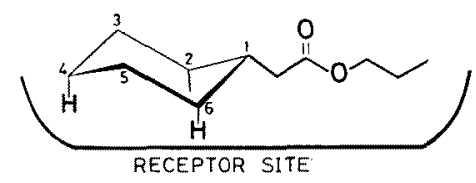

Fig. 1. A Side Elevation View of the Interaction of Propyl Cyclohexaneacetate and the Receptor Site.

As a means to probe the function of the $\mathrm{C}-\mathrm{H}$ bonds in that interaction, propyl cyclohexane-2,2,6,6- $\mathrm{d}_{4-}^{-}$ acetate was prepared and its activity was compared with that of the undeuterated compound.

Cyclohexanone-2,2,6,6- $\mathrm{d}_{4}$ was obtained by treating cyclohexanone with deuterium oxide in the presence of a catalytic amount of $\mathrm{Na}_{2} \mathrm{CO}_{3}{ }^{4}{ }^{4}$ The isotopic purity of the product was $93 \%$ as determined by NMR.

The deuterated as well as undeuterated ketones were converted into propyl cyclohexylideneacetates with 0,O-diethyl carbopropoxymethylphosphonate. ${ }^{5)}$ The double bond was hydrogenated with $\mathrm{NiCl}_{2} \cdot 6 \mathrm{H}_{2} \mathrm{O}+$ $\mathrm{NaBH}_{4}$ to give a corresponding cyclohexaneacetate. ${ }^{3}$ ) The GLC purities were $98 \%$ for the undeuterated compound and $96 \%$ for the deuterated.

Their activities were comparatively tested together with an untreated trap under field conditions in accordance with the previously described procedure ${ }^{12}$ Dish- like traps were constructed from cardboard. They consisted of a $9 \mathrm{~cm}$ square bottom, $5.6 \mathrm{~cm}$ square top, and $2 \mathrm{~cm}$ sides sloping inwards. An adhesive (Polybutene $2000 \mathrm{HB}$ ) was applied onto the bottom interior $1.5 \mathrm{~cm}$ wide from the edge. Filter papers $(4.3 \mathrm{~cm}$ dia.) were placed centrally on the bottom and individually impregnated with measured amounts of test samples. The order of impregnation was altered from test to test.

All the tests were conducted in a room, $335 \times 294 \times$ $245 \mathrm{~cm}$, that had been densely inhabited by the German cockroach, during the summer of 1977 . The room was air-conditioned at $26 \sim 28^{\circ} \mathrm{C}$. Shelters for the insects were provided in both the corners and the center of a shelf, each of which was used as an independent test arena, 10 lux in diffuse light. Three traps including untreated one were placed in each arena at a distance of $15 \mathrm{~cm}$ and exposed over a period of $2 \mathrm{hr}$; the locations of the traps were initially randomized and rerandomized at $0.5 \mathrm{hr}$ intervals. At the end of the experimental period, the captured insects including both adults and nymphs were counted. The test was repeated 6 times at each dose level, thus constituting 12 replications. The tests were performed once or twice a day during the photo-phase of photoperiod of 16L-8D; the 1 st test was alloted to doses less than $1 \mu$ and the 2nd to the dose of $1 \mu 1$.

The activities of the compounds were ranked against the untreated control as well as compared with each other by the Duncan's multiple range test method. The results are shown in Table I. No significant differences could be detected between the captures by the undeuterated and deuterated compounds at any dose level. Nevertheless, when compared with the captures by the untreated controls, the deuterated compound provided significant differences at the three levels. In contrast, the undeuterated compounds invariably failed in giving significant differences from the untreated controls. Hence, as for the attractancy, the

Table I. EFFect of Deuteration on the Attraction of Propyl Cyclohexaneacetate to the German Cockroach

\begin{tabular}{lcccc}
\hline $\begin{array}{c}\text { Combination of } \\
\text { compounds }\end{array}$ & \multicolumn{5}{c}{$\begin{array}{c}\text { Avg no./trap } \\
\text { Dose }(\mu \mathrm{l})\end{array}$} \\
\hline & $0.1^{b}$ & $0.25^{b}$ & 0.5 & 1.0 \\
\cline { 2 - 5 } & $7.3 \mathrm{a}$ & $3.3 \mathrm{~b}$ & $1.4 \mathrm{~b}$ & $4.6 \mathrm{~b}$ \\
$\begin{array}{l}\text { Untreated } \\
\text { Propyl cyclo- } \\
\text { hexaneacetate }\end{array}$ & $13.9 \mathrm{a}$ & $16.4 \mathrm{ab}$ & $14.1 \mathrm{ab}$ & $24.3 \mathrm{ab}$ \\
$\begin{array}{c}\text { Propyl cyclo- } \\
\text { hexane-2,2,6,6- } \\
\mathrm{d}_{4} \text {-acetate }\end{array}$ & $16.4 \mathrm{a}$ & $25.1 \mathrm{a}$ & $17.0 \mathrm{a}$ & $35.7 \mathrm{a}$ \\
\hline
\end{tabular}

a Any pairs of means followed by the same letter in a column are not significantly different at the $5 \%$ level of confidence.

$b$ Applied with $0.5 \mu \mathrm{l}$ solutions in hexane. 
undeuterated compound was ranked between the deuterated compound and the untreated control. This may be regarded as a manifestation of a deuterium effect in insect attraction. This rather subtle effect would be in no way unintelligible. For example, the ratio of stretching vibrational energies of $\mathrm{C}-\mathrm{H}$ and $\mathrm{C}-\mathrm{D}$ bonds is only $\sqrt{2}$. The value is well within 2 , a lower limit of the factors employed in the serial dosing tests of biological activities. The effect of deuteration on the behaviour of insects, if any, could hardly exceed this range, in so far as any kinetic mechanism that intensifies the effect encountered in organic reactions is not involved. This might partly constitute a reason for the unsuccessful detection of a deuterium effect for the cue-lure $^{7)}$ and the ant alarm pheromone. ${ }^{8)}$ Propyl cyclohexaneacetate has the optimum structure among analogous series. ${ }^{2,3}$ Its activity will no less depend upon the $\mathrm{C}-\mathrm{H}$ bonds than upon other components of the molecule. Even so, a favourable effect of deuteration has been indicated only when compared with the untreated controls.

To interpret the effect of the C-D bonds, most probably the axials, two factors must be taken into account. One is a steric effect that brings about an asymmetric induction. ${ }^{9)}$ The C-D bonds somewhat shorter than the $\mathrm{C}-\mathrm{H}$ bond would make possible closer access of the attractant molecule to the receptor site and thus improves the efficacy of the interaction.

The other is a vibrational effect. Deuteration causes the vibrational frequencies of the $\mathrm{C}-\mathrm{H}$ bond at large to shift to the lower side. This would affect the activity. Indeed, the vibrational theories have been repeatedly proposed for the odour, respectively in reference to frequencies in specific regions. ${ }^{10\rangle}$ The remarkable outcome of the present experiment is that the deuteration not only affected but even improved the attractancy. Our present assumption to accommodate this result is as follows. The receptor site originally exists in an energized state. When the attractant molecule correctly binds with the receptor site, it abstracts the energy, leaving an "energy sink" in the receptor site. This sink will induce a flow of energy that finally leads to depolarization of the dendrite. For this effect, the ax.C-H's which perpendicularly point towards and most closely approach the receptor site would constitute one of the most efficacious components. The $\mathrm{C}-\mathrm{H}$ vibrations would couple or resonate with a structure in the receptor site, absorb the energy, and jump up to the next higher levels. Because the allowed energy levels are spaced more closely for the C-D than for the $\mathrm{C}-\mathrm{H}$, the former could relatively easily absorb the energy. The above interpretation might have some analogy with the theory of Wright ${ }^{11}$ ) that postulates de-excitation of the receptor site through a resonance with odourous molecules.

It is also expected that the resonating counterpart such as pigment ${ }^{12)}$ could be substantiated for the receptor site.

\section{REFERENCES}

1) R. Sugawara, S. Kurihara and T. Muto, J. Insect Physiol., 21, 957 (1975).

2) R. Sugawara, Y. Tominaga, M. Kobayashi and T. Muto, ibid., 22, 785 (1976).

3) R. Sugawara, Y. Tominaga and T. Suzuki, Insect Biochem., 7, 483 (1977).

4) L. Lompa-Krzymien and L. C. Leitch, J. Labelled Compd., 9, 331 (1973).

5) A. H. Ford-Moor and B. J. Perry, "Organic Synthesis Coll. Vol. 4," ed. by N. Rabjohn, John Wiley \& Sons, Inc., New York, N.Y., 1963, p. 325.

6) T. Satoh, K. Nanba and S. Suzuki, Chem, Pharm. Bull., 19, 817 (1971).

7) R. E. Doolittle, M. Beroza, I. Keiser and E. L. Schneider, J. Insect Physiol., 14, 1697 (1968).

8) M. S. Blum, R. E. Doolittle and M. Beroza, ibid., 17, 2351 (1971).

9) A. Horeau, A. Nouaille and K. Mislow, J. Am. Chem. Soc., 87, 4957 (1965).

10) R. W. Monclieff, "The Chemical Senses," Leonard Hill Inc., London, 1967, p. 597.

11) R. H. Wright, C. Reid and H. G. V. Evans, Chem. Ind., 1973, 973.

12) M. H. Briggs and R. B. Duncan, Nature, 191, 1310 (1961). 